Coda | Patient portraits

a series by Seema Marwaha

\title{
Brooke McClelland
}

\section{口 Cite as: CMAJ 2021 December 20;193:E1927.} doi: 10.1503/cmaj.211954

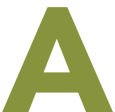
fter years of pelvic pain, multiple hospital visits and 2 surgeries, I breathed a sigh of relief when I finally got a diagnosis of endometriosis that explained my symptoms. When you have profound symptoms but no diagnosis, you feel helpless.

Unfortunately, the pain came back several months after the surgery that led to my diagnosis. It felt like someone was ripping open my insides. I needed to go to the hospital right away.

In the emergency room, I described my cyclical sharp pain. I explained it was identical to the pain I had right before my previous surgery. My expectation was that I would be diagnosed with a recurrence of endometriosis and referred to a gynecologist. But this is not what happened.

At triage, I mentioned that l'd had diarrhea. That became the focus of my workup. I was told endometriosis does not recur this quickly and that gynecology would not see me right away. Instead, I stayed in the hospital for a few days being treated by a medical team that spent a lot of time ruling out other possible causes for my pain with invasive testing. They found microscopic colitis that didn't explain my pain. I was sent home with a few doses of pain killers and told to follow-up with my community gynecologist.

I found it difficult to function and manage my pain after I was discharged. I cried almost every day from pain and started to blame myself for being unable to cope. I was not able to work at full capacity. I needed a flexible schedule for tests and appointments. Medications to help me bridge to surgery were expensive. I was terrified I would become dependent on opioids.
Photo of Brooke McClelland walking the golf course.

It was several months before I was scheduled for surgery again. The operating report said there was "deep infiltrating disease, parametrial disease, and posterior uterus disease with adhesions." My gynecologist found extensive, thick endometriosis that encased my ureter, and a urologist had to be brought in intraoperatively to stent my ureter.

I'm still recovering from that surgery. My debilitating pelvic pain is gone, but I worry that it will come back again. I also worry about my fertility - I'm only 27 . I went through the motions to freeze my eggs before my surgery, but I could not go ahead for several reasons: the cost was high, the required hormone injections might have worsened my symptoms, and timing it before the surgery was almost impossible. My gynecologist reassured me that protecting my fertility was their priority.

Given my experience, I think the process of understanding why a woman might have pelvic pain needs to be faster and less invasive.

Content licence: This is an Open Access article distributed in accordance with the terms of the Creative Commons Attribution (CC BY-NCND 4.0) licence, which permits use, distribution and reproduction in any medium, provided that the original publication is properly cited, the use is noncommercial (i.e., research or educational use), and no modifications or adaptations are made. See: https://creativecommons. org/licenses/by-nc-nd/4.0/ 